\title{
AMT: Preclinical pharmacology studies
}

\author{
FAIZ NIAZI $^{1}$, JOACHIM DREVS $^{2}$, KLAUS DIERGARTEN $^{1}$, ANNETTE DORN $^{5}$, ARMIN MAIER $^{3}$, \\ HEINZ HERBERT FIEBIG ${ }^{3}$, EDDY BRUYNS ${ }^{4}$ and JÜRGEN SCHEELE ${ }^{1}$
}

\author{
${ }^{1}$ Auron Healthcare GmbH, Merzhauser Str. 183, 79100 Freiburg; ${ }^{2}$ Tumorklinik SanaFontis, An den Heilquellen 2, \\ 79111 Freiburg; ${ }^{3}$ Oncotest GmbH, Am Flughafen 12-14, 79108 Freiburg; ${ }^{4}$ FOCUS Clinical Drug Development GmbH, \\ Im Neuenheimer Feld 515, 69120 Heidelberg; ${ }^{5}$ Medizinische Universitätsklinik I, Hugstetterstr. 55, 79106 Freiburg, Germany
}

Received December 12, 2008; Accepted February 5, 2009

DOI: 10.3892/ijo_00000261

\begin{abstract}
Auron-Misheil-Therapy (AMT) consisting of aqueous camomile extract supplemented with calcium, vitamins, the antihistamine chlorpheniramine and human insulin is under development as anti-cancer treatment. AMT was preclinically investigated in tumour cell lines and tumour xenografts to guide clinical phase I/II studies. AMT was tested against 56 human tumour cell lines, in a clonogenic assay in 98 patient-derived xenografts and in in vivo studies. AMT showed in vitro cytotoxic activity with highest susceptibility in cervical cancer, glioblastoma and colon cancers. In the clonogenic assay, anti- cancer activity of AMT was most active in cervical and uterine tumours, in colon cancer, glioblastoma, leukaemia, melanoma and pancreatic cancer. In vivo, AMT showed slight activity in tumour xenograft models of colon and mammary cancer. It also showed immune stimulatory effects by induction of IL-6- and TNF- $\alpha$ secretion in human PBMCs. The immune stimulatory potential of AMT, together with slight anti-tumour efficacy observed in the present study, indicates a role of AMT in tumour therapy.
\end{abstract}

\section{Introduction}

In the search for novel, effective anti-cancer treatments not only pure compounds, usually with known modes of action are investigated, but also natural products or more complex

Correspondence to: Dr Jürgen Scheele, Auron Healthcare GmbH, Merzhauserstr. 183, D-79100 Freiburg, Germany

E-mail: j.scheele@auronhealthcare.com

Abbreviations: AMT, Auron-Misheil-Therapy; ATCC, American Type Culture Collection; DSMZ, Deutsche Sammlung von Mikroorganismen und Zellkulturen; $\mathrm{IC}_{50}, 50 \%$ inhibitory concentration; IFN, interferon; IL, interleukin; LPS, lipopolysaccharide; NCI, National Cancer Institute; PBMC, peripheral blood mononuclear cells; PMA, phorbol-12-myristate-13-acetate; T/C, test/control; TNF, tumour necrosis factor

Key words: anti-tumour activity, immune stimulation, AuronMisheil-Therapy preparations, whose substantial anti-tumour activity may be demonstrated before the precise mechanism of action is fully understood. As an example for the latter ones, aqueous extracts of the European mistletoe (Viscum album L.) have been widely used for decades as alternative or complementary treatment and adjuvant cancer therapy particularly in Germany, Austria and Switzerland (1-5).

Auron-Misheil-Therapy (AMT) is another representative of a more complex formulation. From compassionate use programs among end-stage cancer patients since 1989, preliminary data have provided evidence of benefits in terms of improved quality of life, sometimes together with body weight gain and reduction of pain. AMT is at present under development as an anti-cancer agent in phase II clinical trials.

Preclinical research with AMT revealed pronounced anticancer activity in a range of human tumour models, including bladder, brain, colon, lung, breast, melanoma, prostate and cervix, as well as in cells derived from haematological malignancies, including leukaemias and lymphomas. At the same time, the precise mode of action of AMT remains to be determined. The evidence thus far indicates that its action is predominantly cytotoxic (i.e. actively killing cells) rather than cytostatic (inhibiting mitosis), but the anti-tumour activity of AMT is likely to depend on more than one mechanism, because of the number of different constituents.

This study summarizes the preclinical research with AMT with focus on its anti-tumour and immune stimulatory properties.

\section{Materials and methods}

Test compounds. Auron-Misheil-Therapy (AMT) was provided as sterile, ready-to-use solution by Micro Carrier Systems, Neuss and was stored at $4^{\circ} \mathrm{C}$ until use. The single components of AMT, aqueous camomile extract (derived from $1.8 \mathrm{~g}$ camomile blossom), Calcium Sandoz + Vitamin $\mathrm{C}^{\circledR}$ (Novartis), Becozyme ${ }^{\circledR}$ (vitamin B complex, Roche), Allerfin ${ }^{\circledR}$ (chlorpheniramin maleat, The Arab Pharmaceutical Manufacturing Co. Ltd.), and phenol were provided by Micro Carrier Systems, Neuss. Actrapid HM ${ }^{\circledR}$ (human insulin, Novo Nordisk) was obtained from the pharmacy. All compounds were stored at $4^{\circ} \mathrm{C}$.

For in vitro studies AMT was tested at concentrations ranging from $0.0001 \% \mathrm{v} / \mathrm{v}$ to $10.0 \% \mathrm{v} / \mathrm{v}$. The single compo- 
Table I. Constitution of AMT for testing individual components.

\begin{tabular}{|c|c|c|c|c|}
\hline Component & $\begin{array}{l}\text { Amount in } 100 \mathrm{ml} \\
\text { MISHEIL (ml) }\end{array}$ & $\begin{array}{l}\text { Volume of experimental } \\
\text { approach }(\mathrm{ml})\end{array}$ & $\begin{array}{l}\text { Amount of component } \\
\qquad(\mathrm{ml})\end{array}$ & $\begin{array}{l}\text { Amount of Aqua } \\
\text { injectabilia }(\mathrm{ml})\end{array}$ \\
\hline Camomile extract & 36.146 & 1,000 & 361.46 & 638.54 \\
\hline Calcium Sandoz + Vitamin $C^{\circledR}$ & 35.95 & 1,000 & 359.95 & 640.5 \\
\hline Phenol & 0.25 & 10,000 & 25.0 & 9975.0 \\
\hline Becozyme $^{\circledR}$ & 16.76 & 1,000 & 167.6 & 832.4 \\
\hline Allerfin ${ }^{\circledR}$ & 8.38 & 1,000 & 83.8 & 916.2 \\
\hline Actrapid $^{\circledR}$ & 2.514 & 1,000 & 25.14 & 974.86 \\
\hline
\end{tabular}

nents were tested at their respective final concentrations as they appear in AMT (see Table I). A dilution scheme to prepare AMT is given in Table I. AMT $(100 \mathrm{ml})$ consisted of $36.146 \mathrm{ml}$ aqueous camomile extract, $35.95 \mathrm{ml} \mathrm{Calcium}$ Sandoz + Vitamin $\mathrm{C}^{\circledR}, 0.25 \mathrm{ml}$ Phenol, $16.67 \mathrm{ml} \mathrm{Becozyme}{ }^{\circledR}$, $8.38 \mathrm{ml} \mathrm{Allerfin}{ }^{\circledR}, 2.514 \mathrm{ml}$ Actrapid $\mathrm{HM}^{\circledR}$. Therefore, the single components were diluted with Aqua injectabilia according to Table I and were tested in a dose range of $0.0001 \% \mathrm{v} / \mathrm{v}$ to $10.0 \% \mathrm{v} / \mathrm{v}$. Final dilutions were prepared in cell culture medium.

For in vivo studies the sterile, ready-to-use solution of AMT was administered intramuscularly at doses of 0.12 and $0.06 \mathrm{ml} / \mathrm{mouse}$ daily for up to 22 days. The daily dose was split and applied at hour 0 and 6 . Control mice received saline solution as vehicle $(0.12 \mathrm{ml} / \mathrm{mouse} /$ day $)$ intramuscularly, using the corresponding administration schedule.

5-Fluorouracil (5-FU medac ${ }^{\circledR}$, Medac, Hamburg), dacarbazine (Detimedac ${ }^{\circledR}$, Medac, Hamburg), paclitaxel (Taxol $^{\circledR}$, Bristol-Myers Squibb, Munich), gemcitabine (Gemzar ${ }^{\circledR}$, Lilly, Giessen), cyclophosphamide (Endoxan ${ }^{\circledR}$, Baxter, Frankfurt) were obtained as clinical formulations from the pharmacy and tested at the maximum tolerated dose in an optimized schedule.

Monolayer assay cytotoxicity assay. A modified propidium iodide assay was used to determine the cytotoxic activity of AMT against human tumour cell lines. The test procedure has been described elsewhere (6). Cell lines tested were derived from patient tumours engrafted as a subcutaneously growing tumour in NMRI nu/nu mice, or obtained from the American Type Culture Collection, Rockville, MD, USA, National Cancer Institute, Bethesda, MD, USA, or Deutsche Sammlung von Mikroorganismen und Zellkulturen, Braunschweig, Germany. Briefly, human tumour cell lines were grown at $37^{\circ} \mathrm{C}$ in a humidified atmosphere $\left(95 \%\right.$ air, $\left.5 \% \mathrm{CO}_{2}\right)$ in monolayer cultures in RPMI-1640 medium supplemented with $10 \%$ fetal calf serum and phenol red (PAA, Cölbe, Germany). Cells were trypsinized and maintained weekly. Cells were harvested from exponentially growing cultures by trypsination, counted and plated in 96-well flat-bottomed micro plates (140 $\mu 1$ cell suspension, $5 \times 10^{3}$ to $10 \times 10^{3}$ cells/well). After a $24 \mathrm{~h}$ recovery to allow cells to resume exponential growth, $10 \mu 1$ of culture medium (6 control wells per plate) or medium containing the test drug were added to the wells. Each drug concentration was plated in triplicate. After 4 days of incubation, the culture medium was replaced by fresh medium containing $6 \mu \mathrm{g} / \mathrm{ml}$ of propidium iodide. Microplates were then kept at $-18^{\circ} \mathrm{C}$ for $24 \mathrm{~h}$, to give a total cell kill. After thawing of the plates, fluorescence was measured using the Cytofluor 4000 microplate reader (Perseptive Biosystems) (excitation $530 \mathrm{~nm}$, emission $620 \mathrm{~nm}$ ).

Clonogenic assays with human tumour xenografts and haematopoietic stem cells. Effects of AMT on clonogenicity of tumour cells were investigated in a clonogenic assay. Tumour xenografts were derived from patient tumours engrafted as a subcutaneously growing tumour in NMRI nu/nu mice obtained from Oncotest's breeding facility $(7,8)$. Details of the test procedure have been described earlier (9). Briefly, solid human tumour xenografts were removed from mice under sterile conditions, mechanically disaggregated and subsequently incubated with an enzyme cocktail consisting of collagenase type IV $(41 \mathrm{U} / \mathrm{ml})$, DNase I $(125 \mathrm{U} / \mathrm{ml})$, hyaluronidase type III $(100 \mathrm{U} / \mathrm{ml})$ and dispase II $(1.0 \mathrm{U} / \mathrm{ml})$ in RPMI-1640 medium at $37^{\circ} \mathrm{C}$ for $45 \mathrm{~min}$. Cells were passed through sieves of 200 and $50 \mu \mathrm{m}$ mesh size and washed twice with sterile PBS-buffer. The percentage of viable cells was determined in a Neubauer-hemocytometer using trypan blue exclusion. The bottom layer consisted of $0.2 \mathrm{ml} /$ well Iscove's Modified Dulbecco's Medium (Life Technologies), supplemented with $20 \%$ (v/v) fetal calf serum (Sigma), 0.01\% (w/v) gentamicin (Life Technologies) and $0.75 \%(w / v)$ agar (BD Biosciences). Cells $1.5 \times 10^{4}$ to $4 \times 10^{4}$ were added to $0.2 \mathrm{ml}$ of the same culture medium supplemented with $0.4 \%(\mathrm{w} / \mathrm{v})$ agar and plated in 24-multiwell dishes onto the bottom layer. The test compounds were applied by continuous exposure (drug overlay) in $0.2 \mathrm{ml}$ of culture medium. Every dish included 6 untreated control wells and drug-treated groups in triplicate at 6 concentrations. Cultures were incubated at $37^{\circ} \mathrm{C}$ and $7.5 \% \mathrm{CO}_{2}$ in a humidified atmosphere for 7-20 days and monitored closely for colony growth using an inverted microscope. Within this period, in vitro tumour growth led to the formation of colonies with a diameter of $>50 \mu \mathrm{m}$. At the time of maximum colony formation, counts were performed with an automatic image analysis system (OMNICON 3600, Biosys $\mathrm{GmbH})$. Twenty-four hours prior to evaluation, vital colonies were stained with a sterile aqueous solution of 2-(4iodophenyl)-3-(4-nitrophenyl)-5-phenyltetrazolium chloride ( $1 \mathrm{mg} / \mathrm{ml}, 100 \mu \mathrm{l} /$ well).

For testing haematopoietic stem cells, samples of bone marrow (2 donors) or cord blood (1 donor) were diluted 2- to 3 -fold with PBS containing $0.1 \%$ (w/v) BSA. Mononuclear 
cells were enriched from the respective samples by Ficoll Paque $^{\circledR}$ density gradient centrifugation and washed twice with PBS containing $0.1 \%(\mathrm{w} / \mathrm{v})$ BSA. The resulting cell suspension was stored in aliquots in a freezing medium consisting of $90 \%$ $\mathrm{v} / \mathrm{v}$ fetal calf serum and $10 \% \mathrm{v} / \mathrm{v}$ DMSO at $-80^{\circ} \mathrm{C}$. Aliquots were thawed for testing as appropriate. The colony forming test was performed using 24-well plates and MethoCult GF (Stem Cell Technologies) as culture medium. Twenty-five thousand cells/ml of the above-mentioned preparation were seeded in a final volume of $500 \mu 1$ per well. Solutions of the test compounds were added directly to the medium. Every dish included 6 untreated control wells and drug-treated groups in triplicate at 5 concentrations. Three wells of the test plate were filled with $1 \mathrm{ml}$ of sterile water to ensure that maximum humidity was attained during the subsequent incubation period. Cultures were incubated at $37^{\circ} \mathrm{C}$ and $7.5 \% \mathrm{CO}_{2}$ in a humidified atmosphere for 12 days. Colony growth was evaluated using an inverted microscope (10).

In vivo evaluation in nude mice carrying tumour xenografts. In vivo efficacy of AMT was determined in mice carrying human tumour xenografts, and murine tumours, respectively. All experiments were conducted according to the guidelines of the German Animal Health and Welfare Act (Tierschutzgesetz). Animal health was examined at the day before tumour implantation and before randomization to ensure that only animals of good health were selected to enter testing procedures. The test procedure has been described elsewhere (11). Briefly, tumour fragments of human tumour xenografts were implanted into the flanks of immune-deficient mice of NMRI nu/nu genetic background (Oncotest breeding facility, Freiburg, Germany). Tumour fragments of murine tumours were implanted into the flanks of $\mathrm{C} 57 /$ black 6 mice (Bomholtgard Breeding and Research Center, Ry, Denmark). The fragments were obtained from tumours in serial passage, established either from direct implantation of patient material, or from injection of tumour cell lines obtained from the American Type Culture Collection, Rockville, MD, USA, National Cancer Institute, Bethesda, MD, USA, or Deutsche Sammlung von Mikroorganismen und Zellkulturen, Braunschweig, Germany. Tumour growth was assessed by serial calliper measurements of two perpendicular tumour diameters. Treatment was started when tumours were palpable and reached a median volume of $\sim 100 \mathrm{~mm}^{3}$, depending on tumour type. Each treatment group consisted of 8-11 mice. Animals with appropriate tumour volumes were randomly distributed into treatment and control groups (day 0). Tumour diameters and body weights were recorded twice weekly. For the evaluation of treatment efficacy, tumour volumes were calculated for each time point according to the formula (length $\mathrm{x}$ width $\left.{ }^{2}\right) / 2$ by using specifically designed software and by plotting the median relative tumour volume against time. Relative tumour volumes were calculated for each single tumour by dividing the tumour volume on day $\mathrm{X}$ by the initial tumour volume on day 0 at the time of randomization. A median body weight loss of $>20 \%$ without recovery was considered not evaluable for anti-tumour efficacy. The U-Test by Mann-Whitney-Wilcoxon was used for the statistical analysis of the data based on median relative tumour volume parameters.
Immune stimulation. Peripheral blood mononuclear cells (PBMC) were isolated from freshly drawn human blood treated with EDTA as an anti-coagulant. Cells were diluted with 3 volumes of CliniMACS PBS/EDTA buffer (Miltenyi, Bergisch Gladbach), carefully layered over FicollPaque (GE Healthcare) in a conical tube and centrifuged at $400 \times \mathrm{g}$ for $40 \mathrm{~min}$ at $20^{\circ} \mathrm{C}$ in a swinging-bucket rotor without brake. The upper layer was aspirated, leaving the mononuclear cell layer undisturbed at the interphase. The interphase cells (lymphocytes, monocytes and thrombocytes) were carefully transferred into a new conical tube. This was filled with CliniMACS PBS/EDTA buffer and centrifuged at $300 \mathrm{x}$ g for $10 \mathrm{~min}$ at $20^{\circ} \mathrm{C}$. The supernatant was completely removed. For removal of platelets the cell pellet was resuspended in $50 \mathrm{ml}$ buffer and centrifuged at $200 \mathrm{x} \mathrm{g}$ for $10 \mathrm{~min}$ at $20^{\circ} \mathrm{C}$. The supernatant was completely removed and the last washing step was repeated. Cells were resuspended in AIMV-Medium (Life Technologies, Karlsruhe) and counted in a Neubauerhaemocytometer.

For the stimulation of PBMC 250,000 cells per well were seeded in a 96-well plate. PBMC of 5 different healthy donors were stimulated with AMT $(0.3 \% \mathrm{v} / \mathrm{v})$, or a stimulation cocktail containing PMA $10 \mathrm{ng} / \mathrm{ml}$ (Sigma, Deisenhofen), Ionomycin $1 \mu \mathrm{g} / \mathrm{ml}$ (Sigma) and LPS $1 \mu \mathrm{g} / \mathrm{ml}$ (Linaris, Wertheim-Bettingen), respectively. Cells were incubated at $37^{\circ} \mathrm{C}$ and $5 \% \mathrm{CO}_{2}$ in a humidified atmosphere for $24 \mathrm{~h}$.

The supernatants from the stimulated PBMC were taken immediately before use and tested for cytokines by a cytometric bead assay (CBA). The supernatant from PBMC stimulated with the cocktail containing PMA, Ionomycin and LPS was used as an internal positive control. Before the cytokines were measured, the internal positive control and the AMT supernatants were diluted with CBA assay diluent. The cytokines interleukin (IL)-2, IL-4, IL-6, IL-10, tumour necrosis factor $\alpha$ (TNF- $\alpha$ ) and interferon $\gamma($ IFN- $\gamma$ ) were quantitatively measured with a Coulter Cytomics FC500 cytometer using the CBA (Becton-Dickinson, San Diego) according to the manufacturer's instructions. The results were analyzed with the Coulter Cytomics Bead Array Analysis program.

\section{Results}

Auron-Misheil-Therapy (AMT). AMT is a mixture of approved pharmaceuticals in low therapeutic doses and consists of an aqueous extract of camomile supplemented with calcium, vitamins, the antihistamine chlorpheniramine, and human insulin (Table II). AMT was developed as a supportive therapy for patients with malignancies.

In vitro efficacy tests. In order to investigate its anti-tumour efficacy, AMT was tested in a broad panel of 56 permanent human tumour cell lines reflecting 12 different tumour types in vitro using a proliferation inhibition assay. The cell line panel comprised commercial available cell lines, as well as cell lines established from solid tumour xenografts which were directly derived from patient material. The ready-to-use AMT solution was added at concentrations ranging from $0.001 \% \mathrm{v} / \mathrm{v}$ to $10 \% \mathrm{v} / \mathrm{v}$ to the cell cultures, and inhibition of proliferation was measured. AMT showed concentration-dependent and 
Table II. Formulation of AMT showing final concentrations of single constituents.

\begin{tabular}{lcc} 
Compound & Amount/100 ml Conc. $(\mathrm{mg} / \mathrm{m}$ ) \\
\hline Aqueous camomile & & \\
extract of $1.8 \mathrm{~g}$ blossom & $36.146 \mathrm{ml}$ & - \\
Phenol & $0.25 \mathrm{ml}$ & 2.65 \\
Calciumglubionate & $4943.0 \mathrm{mg}$ & 49.43 \\
Vitamin C & $1797.5 \mathrm{mg}$ & 17.975 \\
Vitamin B1 & $83.8 \mathrm{mg}$ & 0.838 \\
Vitamin B2 & $45.84 \mathrm{mg}$ & 0.4584 \\
Nicotinamide & $335.2 \mathrm{mg}$ & 3.352 \\
Vitamin B6 & $33.52 \mathrm{mg}$ & 0.3352 \\
Vitamin B5 (Dexpanthenol) & $50.28 \mathrm{mg}$ & 0.5028 \\
Chlorpheniramin-maleate & $83.8 \mathrm{mg}$ & 0.838 \\
Human insulin (251.4 I.E.) & $8.8 \mathrm{mg}$ & 0.088 \\
\hline
\end{tabular}

selective inhibition of tumour cell growth. The concentrations of AMT, where 50 or $70 \%$ of the cells were inhibited in proliferation, are given in Table III for each cell line. Cytotoxic activity was most pronounced in the ovarian cancer cell line $\mathrm{A} 2780\left(\mathrm{IC}_{50}=0.16 \% \mathrm{v} / \mathrm{v}\right)$, the cervical cancer cell line SW-756 $\left(\mathrm{IC}_{50}=0.17 \% \mathrm{v} / \mathrm{v}\right)$, and the colon cancer cell line SW-480 $\left(\mathrm{IC}_{50}=0.17 \% \mathrm{v} / \mathrm{v}\right)$. Further, above average activity was observed towards tumour cell lines of glioblastoma (CNXF 498NL, LN-229, SF-268, SF-295, U-87 MG; IC 50 values ranging from $0.32 \% \mathrm{v} / \mathrm{v}$ to $0.52 \% \mathrm{v} / \mathrm{v})$, colon cancer (COLO205, DLD- $1 ; \mathrm{IC}_{50}=0.35 \% \mathrm{v} / \mathrm{v}$ and $0.51 \% \mathrm{v} / \mathrm{v}$ respectively), and towards cell lines of leukaemia and lymphoma (CCRFCEM, HL-60, K-562, MOLT-4, RPMI-8226, U-937; IC 50 values ranging from $0.18 \% \mathrm{v} / \mathrm{v}$ to $0.39 \% \mathrm{v} / \mathrm{v}$ ) (Table III). Tumour cell lines of pancreatic cancer (PAXF 1657L, BXPC3), and renal cancer (RXF 1781L, RXF 393NL, RXF 486L, RXF 944L, CAKI-1) were generally less sensitive (Table III).

Inhibition of clonogenicity of tumour cells by AMT was evaluated in additional tumour models using a clonogenic assay. The anti-proliferative activity of AMT was evaluated in cell suspensions freshly prepared from 98 different human tumour xenografts of 19 tumour types which grew as solid tumours in serial passage on immune-deficient nude mice. In addition, AMT was tested in 3 preparations of haematopoietic stem cells as a model system for non-malignant tissue. AMT inhibited anchorage-independent growth and in vitro colony formation of tumour cells in semi-solid medium. $\mathrm{IC}_{50}$ values in the clonogenic assay ranged from $0.02 \% \mathrm{v} / \mathrm{v}$ to $6.61 \% \mathrm{v} / \mathrm{v}$ (Table IV). Cytotoxic selectivity of AMT for cervical cancer $\left(\right.$ CEXF 633 and CEXF 773, $\mathrm{IC}_{50}=0.35 \% \mathrm{v} / \mathrm{v}$ and $0.38 \% \mathrm{v} / \mathrm{v}$, respectively), glioblastomas $\left(\mathrm{CNXF} 498, \mathrm{IC}_{50}=0.48 \% \mathrm{v} / \mathrm{v}\right)$, and leukaemias (CCRF-CEM and JURKAT, $\mathrm{IC}_{50}=0.02 \% \mathrm{v} / \mathrm{v}$ and $0.19 \% \mathrm{v} / \mathrm{v}$, respectively) could be confirmed (Tables IV and $\mathrm{V}$ ). In addition, considerable inhibition of colony formation was observed against tumour models of melanoma (MEXF 462, MEXF 514, MEXF 535, MEXF 989; $\mathrm{IC}_{50}$ values ranging from $0.06 \% \mathrm{v} / \mathrm{v}$ to $0.5 \% \mathrm{v} / \mathrm{v}$ ), pancreatic cancer (PAXF 1657 and PAXF 546; $\mathrm{IC}_{50}=0.32 \% \mathrm{v} / \mathrm{v}$ and $0.38 \% \mathrm{v} / \mathrm{v}$ respectively), gastric cancer (GXF 251 and GXF 97; $\mathrm{IC}_{50}=0.08 \% \mathrm{v} / \mathrm{v}$ and $0.44 \% \mathrm{v} / \mathrm{v}$ respectively), prostate cancer (PRXF 1369 and PRXF MRI-H-1579; $\mathrm{IC}_{50}=0.18 \% \mathrm{v} / \mathrm{v}$ and $0.39 \% \mathrm{v} / \mathrm{v}$ respectively), as well as against individual models of renal cancer (RXF 393 and RXF 423; $\mathrm{IC}_{50}=0.46 \% \mathrm{v} / \mathrm{v}$ and $0.31 \%$ $\mathrm{v} / \mathrm{v}$ respectively), and colon cancer (CXF 1034, CXF 158, CXF $1753 ; \mathrm{IC}_{50}$ values ranging from $0.24 \% \mathrm{v} / \mathrm{v}$ to $0.41 \% \mathrm{v} / \mathrm{v}$ ) (Tables IV and V). Colony formation of haematopoietic stem cells derived from bone marrow or cord blood was inhibited by AMT with $\mathrm{IC}_{50}$ values between $0.24 \% \mathrm{v} / \mathrm{v}$ and $0.34 \% \mathrm{v} / \mathrm{v}$ (Table IV). Less activity was seen in tumour types such as liver cancer, non-small cell lung cancer and ovarian cancer (Tables IV and V).

The single components of AMT at their respective final concentrations were evaluated separately for anti-tumour activity in comparison to the total AMT preparation in the clonogenic assay. Table II shows the concentrations of the single components as they occur in AMT, when the product is manufactured according to the composition shown in Table I. Four human tumour models, responsive towards AMT, were selected according to the above-mentioned test results, namely LXFA 629 (adeno lung cancer), MAXF 401 (adenocarcinoma of the breast), MEXF 462 (amelanotic melanoma), PAXF 1657 (adenocarcinoma of the pancreas). Fig. 1 shows the results at each drug concentration. AMT showed clear antitumour activity in a concentration range between $0.1 \% \mathrm{v} / \mathrm{v}$ and $10.0 \% \mathrm{v} / \mathrm{v}$, which is in accordance to the response described above. At $1.0 \% \mathrm{v} / \mathrm{v}$ colony formation was inhibited by $>70 \%$ in $3 / 4$ tumour models, and at 3.0 and $10.0 \% \mathrm{v} / \mathrm{v}$, in all tumour models tested. Calcium Sandoz + Vitamin C was active at concentrations of $3.0 \% \mathrm{v} / \mathrm{v}$ (inhibition of $2 / 4$ tumour models) and $10.0 \% \mathrm{v} / \mathrm{v}(4 / 4)$. The aqueous camomile extract was active in 3/4 tumour models at the highest test concentration of $10 \% \mathrm{v} / \mathrm{v}$ (Fig. 1).

Slight inhibitory effects were obtained for Allerfin and Becozyme. Allerfin inhibited colony growth at the highest test concentration in the lung cancer model LXFA 629 and the mammary cancer model MAXF 401 with $\mathrm{T} / \mathrm{C}=30 \%$ in each case, but was inactive in the two other tumour models. Becozyme effected inhibition in colony growth at the highest test concentration in the melanoma model MEXF 462 with $\mathrm{T} / \mathrm{C}=38 \%$, but was totally inactive in all other tumour models. No anti-tumour activity was seen in case of Actrapid HM (Fig. 1). Overall, the activity of AMT was strikingly higher than that of any single component.

In vivo efficacy tests. AMT was tested in six human xenograft models which have been identified to be sensitive to AMT treatment in vitro (see above), as well as in three different models of murine tumours. Anti-tumour efficacy was measured as tumour volume inhibition and growth delay over time. Side effects were determined as lethality and body weight loss. AMT was administered intramuscularly at dose levels of 0.12 and $0.06 \mathrm{ml} /$ mouse daily for up to 22 days. The daily dose was split and applied at hour 0 and 6. Standard anticancer drugs, administered at their maximum tolerated dose and optimal schedule, were used as positive controls. AMT was well tolerated in all experiments with median body weight increase in the range of $2-7 \%$. AMT given at $0.06 \mathrm{ml} / \mathrm{mouse} /$ day showed slight anti-tumour activity in the human mammary 
Table III. Cytotoxic activity of AMT against 56 human tumour cell lines tested in vitro in a monolayer proliferation assay.

\begin{tabular}{|c|c|c|c|}
\hline Tumour type & Tumour cell line & $\mathrm{IC}_{50}(\% \mathrm{v} / \mathrm{v})$ & \\
\hline Colon & $\begin{array}{l}\text { COLO-205 } \\
\text { DLD-1 } \\
\text { HCC-2998 } \\
\text { HCT-116 } \\
\text { HT-29 } \\
\text { SW-480 }\end{array}$ & $\begin{array}{l}0.35 \\
0.51 \\
0.66 \\
1.61 \\
1.61 \\
0.17\end{array}$ & $\begin{array}{l}1 / 2 \text { mean } \mathrm{IC}_{50}<\mathrm{IC}_{50} \leq 2 \text { mean } \mathrm{IC}_{50} \\
1 / 2 \text { mean } \mathrm{IC}_{50}<\mathrm{IC}_{50} \leq 2 \text { mean } \mathrm{IC}_{50} \\
1 / 2 \text { mean } \mathrm{IC}_{50}<\mathrm{IC}_{50} \leq 2 \text { mean } \mathrm{IC}_{50} \\
\mathrm{IC}_{50}>2 \text { mean } \mathrm{IC}_{50} \\
\mathrm{IC}_{50}>2 \text { mean } \mathrm{IC}_{50} \\
\mathrm{IC}_{50} \leq 1 / 2 \text { mean } \mathrm{IC}_{50}\end{array}$ \\
\hline Cervix/Uterus & $\begin{array}{c}\text { DoTc2 } \\
\text { SW-756 } \\
\text { UXF } 1138 \mathrm{~L}\end{array}$ & $\begin{array}{l}0.39 \\
0.17 \\
0.43\end{array}$ & $\begin{array}{l}1 / 2 \text { mean } \mathrm{IC}_{50}<\mathrm{IC}_{50} \leq 2 \text { mean } \mathrm{IC}_{50} \\
\mathrm{IC}_{50} \leq 1 / 2 \text { mean } \mathrm{IC}_{50} \\
1 / 2 \text { mean } \mathrm{IC}_{50}<\mathrm{IC}_{50} \leq 2 \text { mean } \mathrm{IC}_{50}\end{array}$ \\
\hline Central nervous system & $\begin{array}{l}\text { CNXF 498NL } \\
\text { LN-229 } \\
\text { SF-268 } \\
\text { SF-295 } \\
\text { U-87 MG }\end{array}$ & $\begin{array}{l}0.52 \\
0.49 \\
0.32 \\
0.33 \\
0.45\end{array}$ & $\begin{array}{l}1 / 2 \text { mean } \mathrm{IC}_{50}<\mathrm{IC}_{50} \leq 2 \text { mean } \mathrm{IC}_{50} \\
1 / 2 \text { mean } \mathrm{IC}_{50}<\mathrm{IC}_{50} \leq 2 \text { mean } \mathrm{IC}_{50} \\
1 / 2 \text { mean } \mathrm{IC}_{50}<\mathrm{IC}_{50} \leq 2 \text { mean } \mathrm{IC}_{50} \\
1 / 2 \text { mean } \mathrm{IC}_{50}<\mathrm{IC}_{50} \leq 2 \text { mean } \mathrm{IC}_{50} \\
1 / 2 \text { mean } \mathrm{IC}_{50}<\mathrm{IC}_{50} \leq 2 \text { mean } \mathrm{IC}_{50}\end{array}$ \\
\hline Leukaemia & $\begin{array}{l}\text { CCRF-CEM } \\
\text { HL-60 } \\
\text { K-562 } \\
\text { MOLT-4 }\end{array}$ & $\begin{array}{l}0.28 \\
0.22 \\
0.19 \\
0.20\end{array}$ & $\begin{array}{l}1 / 2 \text { mean } \mathrm{IC}_{50}<\mathrm{IC}_{50} \leq 2 \text { mean } \mathrm{IC}_{50} \\
\mathrm{IC}_{50} \leq 1 / 2 \text { mean } \mathrm{IC}_{50} \\
\mathrm{IC}_{50} \leq 1 / 2 \text { mean } \mathrm{IC}_{50} \\
\mathrm{IC}_{50} \leq 1 / 2 \text { mean } \mathrm{IC}_{50}\end{array}$ \\
\hline Lymphoma & $\begin{array}{l}\text { RPMI-8226 } \\
\text { U-937 }\end{array}$ & $\begin{array}{l}0.18 \\
0.39\end{array}$ & $\begin{array}{l}\mathrm{IC}_{50} \leq 1 / 2 \text { mean } \mathrm{IC}_{50} \\
1 / 2 \text { mean } \mathrm{IC}_{50}<\mathrm{IC}_{50} \leq 2 \text { mean } \mathrm{IC}_{50}\end{array}$ \\
\hline Lung, non-small cell & $\begin{array}{l}\text { LXF 1121L } \\
\text { LXF 289L } \\
\text { LXF 526L } \\
\text { LXF 529L } \\
\text { LXF 629L } \\
\text { LXF 66NL } \\
\text { LXF 923L } \\
\text { H460 }\end{array}$ & $\begin{array}{l}0.42 \\
0.51 \\
0.34 \\
0.97 \\
0.71 \\
1.25 \\
1.72 \\
1.86\end{array}$ & $\begin{array}{l}1 / 2 \text { mean } \mathrm{IC}_{50}<\mathrm{IC}_{50} \leq 2 \text { mean } \mathrm{IC}_{50} \\
1 / 2 \text { mean } \mathrm{IC}_{50}<\mathrm{IC}_{50} \leq 2 \text { mean } \mathrm{IC}_{50} \\
1 / 2 \text { mean } \mathrm{IC}_{50}<\mathrm{IC}_{50} \leq 2 \text { mean } \mathrm{IC}_{50} \\
1 / 2 \text { mean } \mathrm{IC}_{50}<\mathrm{IC}_{50} \leq 2 \text { mean } \mathrm{IC}_{50} \\
1 / 2 \text { mean } \mathrm{IC}_{50}<\mathrm{IC}_{50} \leq 2 \text { mean } \mathrm{IC}_{50} \\
\mathrm{IC}_{50}>2 \text { mean } \mathrm{IC}_{50} \\
\mathrm{IC}_{50}>2 \text { mean } \mathrm{IC}_{50} \\
\mathrm{IC}_{50}>2 \text { mean } \mathrm{IC}_{50}\end{array}$ \\
\hline Breast & $\begin{array}{l}\text { MAXF 401NL } \\
\quad \text { MCF-7 } \\
\text { MDA-MB-231 } \\
\text { MDA-MB-453 } \\
\text { MDA-MB-486 }\end{array}$ & $\begin{array}{l}0.29 \\
0.59 \\
0.49 \\
0.51 \\
0.47\end{array}$ & $\begin{array}{l}1 / 2 \text { mean } \mathrm{IC}_{50}<\mathrm{IC}_{50} \leq 2 \text { mean } \mathrm{IC}_{50} \\
1 / 2 \text { mean } \mathrm{IC}_{50}<\mathrm{IC}_{50} \leq 2 \text { mean } \mathrm{IC}_{50} \\
1 / 2 \text { mean } \mathrm{IC}_{50}<\mathrm{IC}_{50} \leq 2 \text { mean } \mathrm{IC}_{50} \\
1 / 2 \text { mean } \mathrm{IC}_{50}<\mathrm{IC}_{50} \leq 2 \text { mean } \mathrm{IC}_{50} \\
1 / 2 \text { mean } \mathrm{IC}_{50}<\mathrm{IC}_{50} \leq 2 \text { mean } \mathrm{IC}_{50}\end{array}$ \\
\hline Melanoma & $\begin{array}{l}\text { MEXF 276L } \\
\text { MEXF 394NL } \\
\text { MEXF 462NL } \\
\text { MEXF 514L } \\
\text { MEXF 520L }\end{array}$ & $\begin{array}{l}0.24 \\
0.54 \\
0.48 \\
0.76 \\
0.55\end{array}$ & $\begin{array}{l}\mathrm{IC}_{50} \leq 1 / 2 \text { mean } \mathrm{IC}_{50} \\
1 / 2 \text { mean } \mathrm{IC}_{50}<\mathrm{IC}_{50} \leq 2 \text { mean } \mathrm{IC}_{50} \\
1 / 2 \text { mean } \mathrm{IC}_{50}<\mathrm{IC}_{50} \leq 2 \text { mean } \mathrm{IC}_{50} \\
1 / 2 \text { mean } \mathrm{IC}_{50}<\mathrm{IC}_{50} \leq 2 \text { mean } \mathrm{IC}_{50} \\
1 / 2 \text { mean } \mathrm{IC}_{50}<\mathrm{IC}_{50} \leq 2 \text { mean } \mathrm{IC}_{50}\end{array}$ \\
\hline Ovary & $\begin{array}{l}\text { OVXF 1619L } \\
\text { OVXF 899L } \\
\text { A2780 } \\
\text { OVCAR-3 } \\
\text { OVCAR-5 } \\
\text { SK-OV-3 }\end{array}$ & $\begin{array}{l}0.49 \\
0.90 \\
0.16 \\
0.66 \\
0.57 \\
1.82\end{array}$ & $\begin{array}{l}1 / 2 \text { mean } \mathrm{IC}_{50}<\mathrm{IC}_{50} \leq 2 \text { mean } \mathrm{IC}_{50} \\
1 / 2 \text { mean } \mathrm{IC}_{50}<\mathrm{IC}_{50} \leq 2 \text { mean } \mathrm{IC}_{50} \\
\mathrm{IC}_{50} \leq 1 / 2 \text { mean } \mathrm{IC}_{50} \\
1 / 2 \text { mean } \mathrm{IC}_{50}<\mathrm{IC}_{50} \leq 2 \text { mean } \mathrm{IC}_{50} \\
1 / 2 \text { mean } \mathrm{IC}_{50}<\mathrm{IC}_{50} \leq 2 \text { mean } \mathrm{IC}_{50} \\
\mathrm{IC}_{50}>2 \text { mean } \mathrm{IC}_{50}\end{array}$ \\
\hline Pancreas & $\begin{array}{l}\text { PAXF 1657L } \\
\text { BxPC3 } \\
\text { PANC-1 }\end{array}$ & $\begin{array}{l}1.87 \\
0.91 \\
0.63\end{array}$ & $\begin{array}{l}\mathrm{IC}_{50}>2 \text { mean } \mathrm{IC}_{50} \\
1 / 2 \text { mean } \mathrm{IC}_{50}<\mathrm{IC}_{50} \leq 2 \text { mean } \mathrm{IC}_{50} \\
1 / 2 \text { mean } \mathrm{IC}_{50}<\mathrm{IC}_{50} \leq 2 \text { mean } \mathrm{IC}_{50}\end{array}$ \\
\hline Prostate & $\begin{array}{l}\text { DU-145 } \\
\text { PC3M } \\
\text { 22RV1 } \\
\text { LNCAP }\end{array}$ & $\begin{array}{l}0.35 \\
0.80 \\
0.52 \\
1.42\end{array}$ & $\begin{array}{l}1 / 2 \text { mean } \mathrm{IC}_{50}<\mathrm{IC}_{50} \leq 2 \text { mean } \mathrm{IC}_{50} \\
1 / 2 \text { mean } \mathrm{IC}_{50}<\mathrm{IC}_{50} \leq 2 \text { mean } \mathrm{IC}_{50} \\
1 / 2 \text { mean } \mathrm{IC}_{50}<\mathrm{IC}_{50} \leq 2 \text { mean } \mathrm{IC}_{50} \\
\mathrm{IC}_{50}>2 \text { mean } \mathrm{IC}_{50}\end{array}$ \\
\hline
\end{tabular}


Table III. Continued.

\begin{tabular}{|c|c|c|c|}
\hline Tumour type & Tumour cell line & $\mathrm{IC}_{50}(\% \mathrm{v} / \mathrm{v})$ & \\
\hline Kidney & $\begin{array}{l}\text { RXF 1781L } \\
\text { RXF 393NL } \\
\text { RXF 486L } \\
\text { RXF 944L } \\
\text { CAKI-1 }\end{array}$ & $\begin{array}{l}1.74 \\
0.75 \\
1.12 \\
0.61 \\
1.64\end{array}$ & $\begin{array}{l}\mathrm{IC}_{50}>2 \text { mean } \mathrm{IC}_{50} \\
1 / 2 \text { mean } \mathrm{IC}_{50}<\mathrm{IC}_{50} \leq 2 \text { mean } \mathrm{IC}_{50} \\
\mathrm{IC}_{50}>2 \text { mean } \mathrm{IC}_{50} \\
1 / 2 \text { mean } \mathrm{IC}_{50}<\mathrm{IC}_{50} \leq 2 \text { mean } \mathrm{IC}_{50} \\
\mathrm{IC}_{50}>2 \text { mean } \mathrm{IC}_{50}\end{array}$ \\
\hline Mean $\mathrm{IC}_{50}$ & & 0.55 & \\
\hline
\end{tabular}

\begin{tabular}{|c|c|c|c|c|c|c|c|}
\hline \multirow[t]{2}{*}{ Compound } & \multirow[t]{2}{*}{ Tumour } & \multicolumn{6}{|c|}{$\mathrm{T} / \mathrm{C}(\%)$ at test concentration $\% \mathrm{v} / \mathrm{v}$} \\
\hline & & 0.001 & 0.01 & 0.1 & 1.0 & 3.0 & 10.0 \\
\hline \multirow[t]{4}{*}{ AMT } & LXFA 629 & 84 & 76 & 92 & 31 & 19 & 1 \\
\hline & MAXF 401 & 97 & 78 & 51 & 0 & 0 & 0 \\
\hline & MEXF 462 & 81 & 82 & 80 & 19 & 2 & 0 \\
\hline & PAXF 1657 & 99 & 90 & 86 & 22 & 0 & 0 \\
\hline \multirow[t]{4}{*}{ Camomile extract } & LXFA 629 & 80 & 80 & 73 & 66 & 64 & 9 \\
\hline & MAXF 401 & 82 & 83 & 81 & 63 & 79 & 4 \\
\hline & MEXF 462 & 95 & 91 & 68 & 65 & 49 & 26 \\
\hline & PAXF 1657 & 100 & 96 & 100 & 94 & 105 & 84 \\
\hline \multirow[t]{4}{*}{ Calcium Sandoz + Vitamin C } & LXFA 629 & 89 & 81 & 75 & 60 & 31 & 8 \\
\hline & MAXF 401 & 70 & 82 & 84 & 66 & 15 & 3 \\
\hline & MEXF 462 & 94 & 89 & 103 & 86 & 2 & 1 \\
\hline & PAXF 1657 & 85 & 82 & 89 & 121 & 100 & 15 \\
\hline \multirow[t]{4}{*}{ Phenol } & LXFA 629 & 89 & 81 & 94 & 93 & 89 & 23 \\
\hline & MAXF 401 & 93 & 71 & 92 & 91 & 75 & 2 \\
\hline & MEXF 462 & 89 & 59 & 87 & 84 & 83 & 29 \\
\hline & PAXF 1657 & 78 & 83 & 78 & 89 & 82 & 77 \\
\hline \multirow[t]{4}{*}{ Allerfin ${ }^{\oplus}$} & LXFA 629 & 83 & 82 & 84 & 103 & 125 & 30 \\
\hline & MAXF 401 & 84 & 88 & 79 & 97 & 91 & 30 \\
\hline & MEXF 462 & 88 & 93 & 94 & 86 & 109 & 115 \\
\hline & PAXF 1657 & 97 & 101 & 87 & 93 & 90 & 91 \\
\hline \multirow[t]{4}{*}{ Becozyme $^{\oplus}$} & LXFA 629 & 85 & 93 & 93 & 81 & 84 & 83 \\
\hline & MAXF 401 & 95 & 85 & 92 & 86 & 95 & 90 \\
\hline & MEXF 462 & 80 & 90 & 88 & 98 & 96 & 38 \\
\hline & PAXF 1657 & 84 & 95 & 94 & 94 & 98 & 93 \\
\hline \multirow[t]{4}{*}{ Actrapid ${ }^{\oplus}$} & LXFA 629 & 83 & 77 & 78 & 80 & 88 & 82 \\
\hline & MAXF 401 & 89 & 90 & 86 & 98 & 115 & 114 \\
\hline & MEXF 462 & 89 & 87 & 91 & 94 & 98 & 70 \\
\hline & PAXF 1657 & 89 & 75 & 76 & 73 & 83 & 87 \\
\hline
\end{tabular}

Figure 1. Anti-tumour activity of AMT and single components thereof in vitro using a clonogenic assay. 
Table IV. Cytotoxic activity of AMT against 98 human tumour xenografts tested in vitro in a clonogenic assay.

\begin{tabular}{|c|c|c|c|}
\hline Tumour type & Tumour xenograft & $\mathrm{IC}_{50}(\% \mathrm{v} / \mathrm{v})$ & \\
\hline Haematopoietic stem cells & $\begin{array}{l}\text { KMGLZ } \\
\text { KMSPL } \\
\text { NSB001 }\end{array}$ & $\begin{array}{l}0.27 \\
0.34 \\
0.24\end{array}$ & $\begin{array}{l}\mathrm{IC}_{50} \leq 1 / 2 \text { mean } \mathrm{IC}_{50} \\
\mathrm{IC}_{50} \leq 1 / 2 \text { mean } \mathrm{IC}_{50} \\
\mathrm{IC}_{50} \leq 1 / 2 \text { mean } \mathrm{IC}_{50}\end{array}$ \\
\hline Bladder & $\begin{array}{l}\text { BXF } 1036 \\
\text { BXF } 1218\end{array}$ & $\begin{array}{l}0.38 \\
0.77\end{array}$ & $\begin{array}{l}\mathrm{IC}_{50} \leq 1 / 2 \text { mean } \mathrm{IC}_{50} \\
1 / 2 \text { mean } \mathrm{IC}_{50}<\mathrm{IC}_{50} \leq 2 \text { mean } \mathrm{IC}_{50}\end{array}$ \\
\hline Cervix/uterus & $\begin{array}{l}\text { CEXF } 633 \\
\text { CEXF } 773 \\
\text { SK-UT-1B }\end{array}$ & $\begin{array}{l}2.35 \\
0.35 \\
0.38\end{array}$ & $\begin{array}{l}\mathrm{IC}_{50}>2 \text { mean } \mathrm{IC}_{50} \\
\mathrm{IC}_{50} \leq 1 / 2 \text { mean } \mathrm{IC}_{50} \\
\mathrm{IC}_{50} \leq 1 / 2 \text { mean } \mathrm{IC}_{50}\end{array}$ \\
\hline Glioblastoma & $\begin{array}{l}\text { CNXF } 498 \\
\text { SF-268 }\end{array}$ & $\begin{array}{l}0.30 \\
0.48\end{array}$ & $\begin{array}{l}\mathrm{IC}_{50} \leq 1 / 2 \text { mean } \mathrm{IC}_{50} \\
\mathrm{IC}_{50} \leq 1 / 2 \text { mean } \mathrm{IC}_{50}\end{array}$ \\
\hline Colon & $\begin{array}{l}\text { CXF } 1034 \\
\text { CXF } 1044 \\
\text { CXF } 1103 \\
\text { CXF } 1297 \\
\text { CXF } 1299 \\
\text { CXF } 158 \\
\text { CXF } 1729 \\
\text { CXF } 1753 \\
\text { CXF } 1784 \\
\text { CXF } 243 \\
\text { CXF } 264 \\
\text { CXF } 280 \\
\text { CXF } 647 \\
\text { CXF } 676 \\
\text { CXF } 886\end{array}$ & $\begin{array}{l}0.64 \\
0.41 \\
4.53 \\
0.64 \\
6.61 \\
0.28 \\
1.15 \\
0.24 \\
4.55 \\
1.36 \\
4.92 \\
0.77 \\
1.36 \\
3.07 \\
0.55\end{array}$ & $\begin{array}{l}1 / 2 \text { mean } \mathrm{IC}_{50}<\mathrm{IC}_{50} \leq 2 \text { mean } \mathrm{IC}_{50} \\
\mathrm{IC}_{50} \leq 1 / 2 \text { mean } \mathrm{IC}_{50} \\
\mathrm{ICV}>2 \text { mean } \mathrm{IC}_{50} \\
\mathrm{IC}_{50} \leq 1 / 2 \text { mean } \mathrm{IC}_{50} \\
\mathrm{IC}_{50}>2 \text { mean } \mathrm{IC}_{50} \\
\mathrm{IC}_{50} \leq 1 / 2 \text { mean } \mathrm{IC}_{50} \\
1 / 2 \text { mean } \mathrm{IC}_{50}<\mathrm{IC}_{50} \leq 2 \text { mean } \mathrm{IC}_{50} \\
\mathrm{IC}_{50} \leq 1 / 2 \text { mean } \mathrm{IC}_{50} \\
\mathrm{IC}_{50}>2 \text { mean } \mathrm{IC}_{50} \\
1 / 2 \text { mean } \mathrm{IC}_{50}<\mathrm{IC}_{50} \leq 2 \text { mean } \mathrm{IC}_{50} \\
\mathrm{IC}_{50}>2 \text { mean } \mathrm{IC}_{50} \\
1 / 2 \text { mean } \mathrm{IC}_{50}<\mathrm{IC}_{50} \leq 2 \text { mean } \mathrm{IC}_{50} \\
1 / 2 \text { mean } \mathrm{IC}_{50}<\mathrm{IC}_{50} \leq 2 \text { mean } \mathrm{IC}_{50} \\
\mathrm{IC}_{50}>2 \text { mean } \mathrm{IC}_{50} \\
1 / 2 \text { mean } \mathrm{IC}_{50}<\mathrm{IC}_{50} \leq 2 \text { mean } \mathrm{IC}_{50}\end{array}$ \\
\hline Stomach & $\begin{array}{l}\text { GXF } 1172 \\
\text { GXF } 209 \\
\text { GXF } 251 \\
\text { GXF } 97\end{array}$ & $\begin{array}{l}1.03 \\
3.92 \\
0.08 \\
0.44\end{array}$ & $\begin{array}{l}1 / 2 \text { mean } \mathrm{IC}_{50}<\mathrm{IC}_{50} \leq 2 \text { mean } \mathrm{IC}_{50} \\
\mathrm{IC}_{50}>2 \text { mean } \mathrm{IC}_{50} \\
\mathrm{IC}_{50} \leq 1 / 2 \text { mean } \mathrm{IC}_{50} \\
\mathrm{IC}_{50} \leq 1 / 2 \text { mean } \mathrm{IC}_{50}\end{array}$ \\
\hline Head and neck & $\begin{array}{l}\text { HNXF } 536 \\
\text { HNXF } 908\end{array}$ & $\begin{array}{l}5.27 \\
0.57\end{array}$ & $\begin{array}{l}\mathrm{IC}_{50}>2 \text { mean } \mathrm{IC}_{50} \\
1 / 2 \text { mean } \mathrm{IC}_{50}<\mathrm{IC}_{50} \leq 2 \text { mean } \mathrm{IC}_{50}\end{array}$ \\
\hline Leukaemia & $\begin{array}{l}\text { CCRF-CEM } \\
\text { JURKAT }\end{array}$ & $\begin{array}{l}0.02 \\
0.19\end{array}$ & $\begin{array}{l}\mathrm{IC}_{50} \leq 1 / 2 \text { mean } \mathrm{IC}_{50} \\
\mathrm{IC}_{50} \leq 1 / 2 \text { mean } \mathrm{IC}_{50}\end{array}$ \\
\hline Lymphoma & RAJI & 1.62 & $1 / 2$ mean $\mathrm{IC}_{50}<\mathrm{IC}_{50} \leq 2$ mean $\mathrm{IC}_{50}$ \\
\hline Myeloma & L-363 & 0.71 & $1 / 2$ mean $\mathrm{IC}_{50}<\mathrm{IC}_{50} \leq 2$ mean $\mathrm{IC}_{50}$ \\
\hline Liver & $\begin{array}{l}\text { LIXF } 1788 \\
\text { LIXF } 1791 \\
\text { LIXF } 575 \\
\text { HEP-G2 }\end{array}$ & $\begin{array}{l}0.50 \\
5.55 \\
2.02 \\
2.47\end{array}$ & $\begin{array}{l}1 / 2 \text { mean } \mathrm{IC}_{50}<\mathrm{IC}_{50} \leq 2 \text { mean } \mathrm{IC}_{50} \\
\mathrm{IC}_{50}>2 \text { mean } \mathrm{IC}_{50} \\
\mathrm{IC}_{50}>2 \text { mean } \mathrm{IC}_{50} \\
\mathrm{IC}_{50}>2 \text { mean } \mathrm{IC}_{50}\end{array}$ \\
\hline Lung, adenocarcinoma & $\begin{array}{l}\text { LXFA } 1012 \\
\text { LXFA } 289 \\
\text { LXFA } 297 \\
\text { LXFA } 526 \\
\text { LXFA } 592 \\
\text { LXFA } 629 \\
\text { LXFA } 677 \\
\text { LXFA } 749 \\
\text { LXFA } 923 \\
\text { LXFA } 983 \\
\text { A-549 } \\
\text { PC-14 }\end{array}$ & $\begin{array}{l}0.23 \\
3.54 \\
5.18 \\
2.03 \\
0.44 \\
0.12 \\
2.30 \\
3.07 \\
4.41 \\
1.98 \\
5.40 \\
1.63\end{array}$ & $\begin{array}{l}\mathrm{IC}_{50} \leq 1 / 2 \text { mean } \mathrm{IC}_{50} \\
\mathrm{IC}_{50}>2 \text { mean } \mathrm{IC}_{50} \\
\mathrm{IC}_{50}>2 \text { mean } \mathrm{IC}_{50} \\
\mathrm{IC}_{50}>2 \text { mean } \mathrm{IC}_{50} \\
\mathrm{IC}_{50} \leq 1 / 2 \text { mean } \mathrm{IC}_{50} \\
\mathrm{IC}_{50} \leq 1 / 2 \text { mean } \mathrm{IC}_{50} \\
\mathrm{IC}_{50}>2 \text { mean } \mathrm{IC}_{50} \\
\mathrm{IC}_{50}>2 \text { mean } \mathrm{IC}_{50} \\
\mathrm{IC}_{50}>2 \text { mean } \mathrm{IC}_{50} \\
1 / 2 \text { mean } \mathrm{IC}_{50}<\mathrm{IC}_{50} \leq 2 \text { mean } \mathrm{IC}_{50} \\
\mathrm{IC}_{50}>2 \text { mean } \mathrm{IC}_{50} \\
1 / 2 \text { mean } \mathrm{IC}_{50}<\mathrm{IC}_{50} \leq 2 \text { mean } \mathrm{IC}_{50}\end{array}$ \\
\hline
\end{tabular}


Table IV. Continued.

\begin{tabular}{|c|c|c|c|}
\hline Tumour type & Tumour xenograft & $\mathrm{IC}_{50}(\% \mathrm{v} / \mathrm{v})$ & \\
\hline Lung, squamous cell & $\begin{array}{l}\text { LXFE } 211 \\
\text { LXFE } 397 \\
\text { LXFE } 409\end{array}$ & $\begin{array}{l}1.89 \\
1.57 \\
3.54\end{array}$ & $\begin{array}{l}1 / 2 \text { mean } \mathrm{IC}_{50}<\mathrm{IC}_{50} \leq 2 \text { mean } \mathrm{IC}_{50} \\
1 / 2 \text { mean } \mathrm{IC}_{50}<\mathrm{IC}_{50} \leq 2 \text { mean } \mathrm{IC}_{50} \\
\mathrm{IC}_{50}>2 \text { mean } \mathrm{IC}_{50}\end{array}$ \\
\hline Lung, large cell & $\begin{array}{l}\text { LXFL } 1072 \\
\text { LXFL } 1176 \\
\text { LXFL 430LX } \\
\text { LXFL } 529\end{array}$ & $\begin{array}{l}1.61 \\
1.76 \\
0.29 \\
0.88\end{array}$ & $\begin{array}{l}1 / 2 \text { mean } \mathrm{IC}_{50}<\mathrm{IC}_{50} \leq 2 \text { mean } \mathrm{IC}_{50} \\
1 / 2 \text { mean } \mathrm{IC}_{50}<\mathrm{IC}_{50} \leq 2 \text { mean } \mathrm{IC}_{50} \\
\mathrm{IC}_{50} \leq 1 / 2 \text { mean } \mathrm{IC}_{50} \\
1 / 2 \text { mean } \mathrm{IC}_{50}<\mathrm{IC}_{50} \leq 2 \text { mean } \mathrm{IC}_{50}\end{array}$ \\
\hline Breast & $\begin{array}{l}\text { MAXF } 1162 \\
\text { MAXF } 1322 \\
\text { MAXF } 1384 \\
\text { MAXF } 401 \\
\text { MAXF } 449 \\
\text { MAXF } 574 \\
\text { MAXF } 583 \\
\text { MAXF } 857 \\
\text { MCF-7 } \\
\text { MDA-MB-231 } \\
\text { MX1 }\end{array}$ & $\begin{array}{l}0.78 \\
2.05 \\
1.00 \\
0.19 \\
1.30 \\
0.56 \\
5.19 \\
1.57 \\
1.54 \\
1.53 \\
0.52\end{array}$ & $\begin{array}{l}1 / 2 \text { mean } \mathrm{IC}_{50}<\mathrm{IC}_{50} \leq 2 \text { mean } \mathrm{IC}_{50} \\
\mathrm{IC}_{50}>2 \text { mean } \mathrm{IC}_{50} \\
1 / 2 \text { mean } \mathrm{IC}_{50}<\mathrm{IC}_{50} \leq 2 \text { mean } \mathrm{IC}_{50} \\
\mathrm{IC}_{50} \leq 1 / 2 \text { mean } \mathrm{IC}_{50} \\
1 / 2 \text { mean } \mathrm{IC}_{50}<\mathrm{IC}_{50} \leq 2 \text { mean } \mathrm{IC}_{50} \\
1 / 2 \text { mean } \mathrm{IC}_{50}<\mathrm{IC}_{50} \leq 2 \text { mean } \mathrm{IC}_{50} \\
\mathrm{IC}_{50}>2 \text { mean } \mathrm{IC}_{50} \\
1 / 2 \text { mean } \mathrm{IC}_{50}<\mathrm{IC}_{50} \leq 2 \text { mean } \mathrm{IC}_{50} \\
1 / 2 \text { mean } \mathrm{IC}_{50}<\mathrm{IC}_{50} \leq 2 \text { mean } \mathrm{IC}_{50} \\
1 / 2 \text { mean } \mathrm{IC}_{50}<\mathrm{IC}_{50} \leq 2 \text { mean } \mathrm{IC}_{50} \\
1 / 2 \text { mean } \mathrm{IC}_{50}<\mathrm{IC}_{50} \leq 2 \text { mean } \mathrm{IC}_{50}\end{array}$ \\
\hline Melanoma & $\begin{array}{l}\text { MEXF } 1341 \\
\text { MEXF } 276 \\
\text { MEXF } 462 \\
\text { MEXF } 514 \\
\text { MEXF } 535 \\
\text { MEXF } 672 \\
\text { MEXF } 989 \\
\text { HT-144 }\end{array}$ & $\begin{array}{l}1.72 \\
1.90 \\
0.43 \\
0.50 \\
0.33 \\
1.17 \\
0.06 \\
1.53\end{array}$ & $\begin{array}{l}1 / 2 \text { mean } \mathrm{IC}_{50}<\mathrm{IC}_{50} \leq 2 \text { mean } \mathrm{IC}_{50} \\
1 / 2 \text { mean } \mathrm{IC}_{50}<\mathrm{IC}_{50} \leq 2 \text { mean } \mathrm{IC}_{50} \\
\mathrm{IC}_{50} \leq 1 / 2 \text { mean } \mathrm{IC}_{50} \\
\mathrm{IC}_{50} \leq 1 / 2 \text { mean } \mathrm{IC}_{50} \\
\mathrm{IC}_{50} \leq 1 / 2 \text { mean } \mathrm{IC}_{50} \\
1 / 2 \text { mean } \mathrm{IC}_{50}<\mathrm{IC}_{50} \leq 2 \text { mean } \mathrm{IC}_{50} \\
\mathrm{IC}_{50} \leq 1 / 2 \text { mean } \mathrm{IC}_{50} \\
1 / 2 \text { mean } \mathrm{IC}_{50}<\mathrm{IC}_{50} \leq 2 \text { mean } \mathrm{IC}_{50}\end{array}$ \\
\hline Ovary & $\begin{array}{l}\text { OVXF } 1023 \\
\text { OVXF } 550 \\
\text { OVXF } 899 \\
\text { SK-OV-3 }\end{array}$ & $\begin{array}{l}1.60 \\
2.17 \\
2.34 \\
2.06\end{array}$ & $\begin{array}{l}1 / 2 \text { mean } \mathrm{IC}_{50}<\mathrm{IC}_{50} \leq 2 \text { mean } \mathrm{IC}_{50} \\
\mathrm{IC}_{50}>2 \text { mean } \mathrm{IC}_{50} \\
\mathrm{IC}_{50}>2 \text { mean } \mathrm{IC}_{50} \\
\mathrm{IC}_{50}>2 \text { mean } \mathrm{IC}_{50}\end{array}$ \\
\hline Pancreas & $\begin{array}{l}\text { PAXF } 1657 \\
\text { PAXF } 546 \\
\text { PAXF } 736 \\
\text { MIA PaCa-2 }\end{array}$ & $\begin{array}{l}0.32 \\
0.38 \\
0.66 \\
1.74\end{array}$ & $\begin{array}{l}\mathrm{IC}_{50} \leq 1 / 2 \text { mean } \mathrm{IC}_{50} \\
\mathrm{IC}_{50} \leq 1 / 2 \text { mean } \mathrm{IC}_{50} \\
1 / 2 \text { mean } \mathrm{IC}_{50}<\mathrm{IC}_{50} \leq 2 \text { mean } \mathrm{IC}_{50} \\
1 / 2 \text { mean } \mathrm{IC}_{50}<\mathrm{IC}_{50} \leq 2 \text { mean } \mathrm{IC}_{50}\end{array}$ \\
\hline Prostate & $\begin{array}{l}\text { PRXF } 1369 \\
\text { 22RV1 } \\
\text { DU-145 } \\
\text { MRI-H-1579 } \\
\text { PC3M }\end{array}$ & $\begin{array}{l}0.18 \\
2.80 \\
1.17 \\
0.39 \\
4.99\end{array}$ & $\begin{array}{l}\mathrm{IC}_{50} \leq 1 / 2 \text { mean } \mathrm{IC}_{50} \\
\mathrm{IC}_{50}>2 \text { mean } \mathrm{IC}_{50} \\
1 / 2 \text { mean } \mathrm{IC}_{50}<\mathrm{IC}_{50} \leq 2 \text { mean } \mathrm{IC}_{50} \\
\mathrm{IC}_{50} \leq 1 / 2 \text { mean } \mathrm{IC}_{50} \\
\mathrm{IC}_{50}>2 \text { mean } \mathrm{IC}_{50}\end{array}$ \\
\hline Kidney & $\begin{array}{c}\text { RXF } 1220 \\
\text { RXF } 1393 \\
\text { RXF } 393 \\
\text { RXF } 423 \\
\text { RXF 631 } \\
\text { RXF 944LX }\end{array}$ & $\begin{array}{l}1.87 \\
2.43 \\
0.46 \\
0.31 \\
1.56 \\
2.11\end{array}$ & $\begin{array}{l}1 / 2 \text { mean } \mathrm{IC}_{50}<\mathrm{IC}_{50} \leq 2 \text { mean } \mathrm{IC}_{50} \\
\mathrm{ICV}>2 \text { mean } \mathrm{IC}_{50} \\
\mathrm{IC}_{50} \leq 1 / 2 \text { mean } \mathrm{IC}_{50} \\
\mathrm{IC}_{50} \leq 1 / 2 \text { mean } \mathrm{IC}_{50} \\
1 / 2 \text { mean } \mathrm{IC}_{50}<\mathrm{IC}_{50} \leq 2 \text { mean } \mathrm{IC}_{50} \\
\mathrm{IC}_{50}>2 \text { mean } \mathrm{IC}_{50}\end{array}$ \\
\hline Sarcoma & $\begin{array}{l}\text { SXF } 1186 \\
\text { SXF } 1301 \\
\text { SXF } 1410 \\
\text { SXF } 463 \\
\text { SXF } 627\end{array}$ & $\begin{array}{l}5.04 \\
1.73 \\
0.35 \\
1.97 \\
1.87\end{array}$ & $\begin{array}{l}\mathrm{IC}_{50}>2 \text { mean } \mathrm{IC}_{50} \\
1 / 2 \text { mean } \mathrm{IC}_{50}<\mathrm{IC}_{50} \leq 2 \text { mean } \mathrm{IC}_{50} \\
\mathrm{IC}_{50} \leq 1 / 2 \text { mean } \mathrm{IC}_{50} \\
1 / 2 \text { mean } \mathrm{IC}_{50}<\mathrm{IC}_{50} \leq 2 \text { mean } \mathrm{IC}_{50} \\
1 / 2 \text { mean } \mathrm{IC}_{50}<\mathrm{IC}_{50} \leq 2 \text { mean } \mathrm{IC}_{50}\end{array}$ \\
\hline Mean $\mathrm{IC}_{50}$ & & 1.0 & \\
\hline
\end{tabular}


Table V. Tumour type selectivity of AMT in human tumour xenografts tested in vitro in a clonogenic assay.

\begin{tabular}{lcc}
\hline & \multicolumn{2}{c}{ Anti-tumour selectivity } \\
\cline { 2 - 3 } Tumour type & Sensitivity & Resistance $^{\mathrm{b}}$ \\
\hline Cervix/Uterus & $3 / 3$ & $0 / 3$ \\
Leukaemia & $2 / 2$ & $0 / 2$ \\
Melanoma & $4 / 8$ & $0 / 8$ \\
Stomach & $2 / 4$ & $1 / 4$ \\
Pancreas & $2 / 4$ & $0 / 4$ \\
CNS & $1 / 2$ & $0 / 2$ \\
Prostate & $2 / 5$ & $2 / 5$ \\
Kidney & $2 / 6$ & $2 / 6$ \\
Bladder & $1 / 3$ & $1 / 3$ \\
Colon & $3 / 14$ & $5 / 14$ \\
Lung NSCL & $4 / 19$ & $8 / 19$ \\
Sarcoma & $1 / 5$ & $1 / 5$ \\
Mammary & $1 / 11$ & $2 / 11$ \\
Head and neck & $0 / 2$ & $1 / 2$ \\
Lymphoma & $0 / 2$ & $0 / 2$ \\
Liver & $0 / 4$ & $3 / 4$ \\
Ovary & $0 / 4$ & $3 / 4$ \\
28/98 & $29 / 98$ & \\
\hline
\end{tabular}

andividual $\mathrm{IC}_{50}<1 / 2$ mean $\mathrm{IC}_{50}$ of all tumours and bindividual $\mathrm{IC}_{50}$. cancer model MAXF 401 (optimal T/C of 71\%), as well as in the murine melanoma B-16 (optimal $\mathrm{T} / \mathrm{C}$ of $63 \%$ ), and given at $0.12 \mathrm{ml} / \mathrm{mouse} /$ day in the murine colon adenocarcinoma colon 38 (optimal T/C of 65\%) (Table VI). AMT revealed the greatest inhibitory effect in the human colon cancer model CXF 1753 with an optimal T/C of $67 \%$ at $0.06 \mathrm{ml} / \mathrm{mouse}$ on day 28 which was significant $(\mathrm{p}<0.05)$ (Table VI, Fig. 2). Anti-tumour efficacy was generally not strictly dosedependent. CXF 1753 responded to the positive control 5fluorouracil which was given at $100 \mathrm{mg} / \mathrm{kg} / \mathrm{d}$ i.p. on days 0 , 7 and 14 with an optimal T/C value of $27 \%$ on day 28 (Fig. 2).

The human melanoma MEXF 989, the lung adenocarcinoma LXFA 629, the pancreatic adenocarcinoma PAXF 1657, and the leukaemia CCRF-CEM (optimal T/C values ranging from 78 to $100 \%$ ) and the murine Lewis lung adenocarcinoma (optimal T/C of $84 \%$ ) were resistant to AMT treatment (Table VI). The standard anti-cancer drugs used as positive controls, dacarbazine (MEXF 989), paclitaxel (LXFA 629), gemcitabine (PAXF 1657), cyclophosphamide (CCRF-CEM), showing significant inhibition of tumour growth in each case (Table VI).

Immune stimulatory effects. The immune stimulating of AMT was investigated on PBMCs of five different healthy donors. AMT was tested at a subtoxic concentration of $0.3 \% \mathrm{v} / \mathrm{v}$. The secretion of IL-2, IL-4, IL-6, IL-10, TNF- $\alpha$ and IFN- $\gamma$ was quantitatively measured by flow cytometry. AMT clearly

Table VI. Inhibition of tumour growth by AMT tested in vivo in tumour-bearing mice.

\begin{tabular}{|c|c|c|c|c|c|}
\hline \multirow[b]{2}{*}{ Tumour type } & \multirow[b]{2}{*}{ Tumour model } & \multicolumn{2}{|c|}{ AMT } & \multicolumn{2}{|c|}{ Positive controls } \\
\hline & & Dose $(\mathrm{ml} / \mathrm{mouse} / \text { day })^{\mathrm{a}}$ & Optimum T/C (\%) & Compound $^{\mathrm{b}}$ & Optimum T/C (\%) \\
\hline Human colon cancer & CXF 1753 & $\begin{array}{l}0.12 \\
0.06\end{array}$ & $\begin{array}{l}68 \\
67\end{array}$ & $\begin{array}{c}\text { 5-Fluorouracil } \\
\left(5-F U \text { medac }^{\circledR}\right)\end{array}$ & 27 \\
\hline Human lung cancer & LXFA 629 & $\begin{array}{l}0.12 \\
0.06\end{array}$ & $\begin{array}{l}87 \\
96\end{array}$ & $\begin{array}{l}\text { Paclitaxel } \\
\left(\text { Taxol }^{\circledR}\right)\end{array}$ & 4 \\
\hline Human breast cancer & MAXF 401 & $\begin{array}{l}0.12 \\
0.06\end{array}$ & $\begin{array}{l}93 \\
71\end{array}$ & $\begin{array}{l}\text { Paclitaxel } \\
\left(\text { Taxol }^{\circledR}\right)\end{array}$ & 0 \\
\hline Human melanoma & MEXF 989 & $\begin{array}{l}0.12 \\
0.06\end{array}$ & $\begin{array}{l}100 \\
100\end{array}$ & $\begin{array}{l}\text { Dacarbazine } \\
\left(\text { Detimedac }^{\circledR}\right)\end{array}$ & 0 \\
\hline Human pancreatic cancer & PAXF 1657 & $\begin{array}{l}0.12 \\
0.06\end{array}$ & $\begin{array}{l}86 \\
95\end{array}$ & $\begin{array}{l}\text { Gemcitabine } \\
\left(\operatorname{Gemzar}^{\circledR}\right)\end{array}$ & 53 \\
\hline Human leukaemia & CCRF-CEM & $\begin{array}{l}0.12 \\
0.06\end{array}$ & $\begin{array}{l}100 \\
100\end{array}$ & $\begin{array}{l}\text { Cyclophosphamide } \\
\left(\text { Endoxan }^{\circledR}\right)\end{array}$ & 0 \\
\hline Murine colon carcinoma & Colon 38 & $\begin{array}{l}0.12 \\
0.06\end{array}$ & $\begin{array}{l}65 \\
76\end{array}$ & n.d. & n.a. \\
\hline Murine lung cancer & Lewis lung & $\begin{array}{l}0.12 \\
0.06\end{array}$ & $\begin{array}{l}92 \\
84\end{array}$ & n.d. & n.a. \\
\hline Murine melanoma & B-16 & $\begin{array}{l}0.12 \\
0.06\end{array}$ & $\begin{array}{l}71 \\
63\end{array}$ & n.d. & n.a. \\
\hline
\end{tabular}

${ }^{\text {a } A M T ~ w a s ~ g i v e n ~ d a i l y ~ f o r ~ u p ~ t o ~} 22$ consecutive days, with the daily dose split into two administrations. boses of positive controls: 5 -Fluorouracil $100 \mathrm{mg} / \mathrm{kg} / \mathrm{d}$ i.p. on days 0, 7, 14; Paclitaxel $20 \mathrm{mg} / \mathrm{kg} / \mathrm{d}$ i.v. on days 0, 7, 14; Dacarbazine $300 \mathrm{mg} / \mathrm{kg} / \mathrm{d}$ i.p. on day d 0; Gemcitabine 300 $\mathrm{mg} / \mathrm{kg} / \mathrm{d}$ i.v. on days 1 and 15; Cyclophosphamide $200 \mathrm{mg} / \mathrm{kg}$ i.p. on days 0 and 14 . n.d., not done and n.a, not available. 


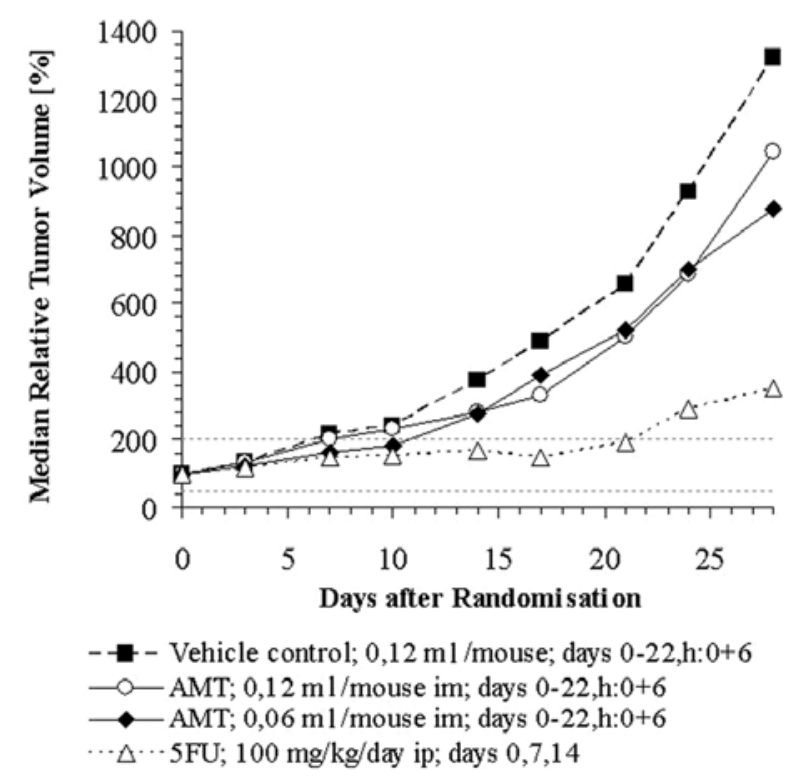

Figure 2. In vivo anti-tumour efficacy of AMT in the human colon adenocarcinoma model CXF 1753.

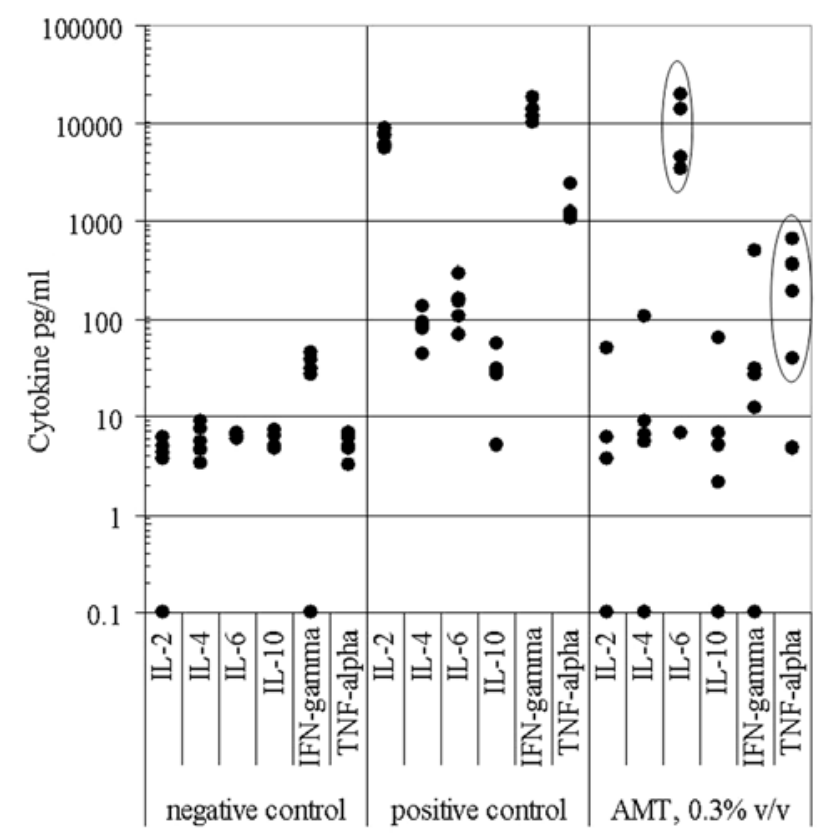

Figure 3. Induction of cytokine secrection by AMT compared to background and positive control (LPS, PMA, ionomycin).

induced the secretion of the cytokines IL- 6 and TNF- $\alpha$ in $4 / 5$ donors. Levels of detected IL- 6 were in the range between 3.4 and $20.0 \mathrm{ng} / \mathrm{ml}$ at $0.3 \% \mathrm{v} / \mathrm{v}$ AMT, compared to a IL-6 secretion range of 0.067 to $0.29 \mathrm{ng} / \mathrm{ml}$ in case of the positive control (a stimulation cocktail of LPS, PMA and ionomycin) in these donor preparations (Fig. 3). TNF- $\alpha$ levels in successfully stimulated blood samples were between 0.04 and $0.65 \mathrm{ng} /$ $\mathrm{ml}$ in case of AMT $(0.3 \% \mathrm{v} / \mathrm{v})$ and between 1.1 and $2.4 \mathrm{ng} / \mathrm{ml}$ in case of the positive control (Fig. 3). Background levels of IL-6 and TNF- $\alpha$ in unstimulated PBMCs were $<0.007 \mathrm{ng} / \mathrm{ml}$ (Fig. 3). In addition, a moderate elevation of IL-2, IL-4 and IL-10 could be detected in individual blood samples, but this effect was not consistent among all samples investigated (Fig. 3).

\section{Discussion}

In contrast to pure compounds with defined chemical structure, the basis of AMT is an aqueous extract of camomile, supplemented with calcium, several vitamins, the antihistamine chlorpheniramine, and human insulin. Despite the difficulty of allocating an active principle in such a complex compound mixture with the therapeutic use of such preparations, the therapeutic use of phytotherapeutic medicines is generally accepted, e.g. the use of St. John's Wort as antidepressant for treatment of mild to moderately severe depression (12-14), the sleep enhancing effect of valerian (15), or the use of aqueous extracts of the European mistletoe (Viscum album L.) as alternative treatment and adjuvant cancer therapy particularly in Germany, Austria and Switzerland (1-5). The objective of the present study was to investigate anti-tumour efficacy of AMT in vitro and in vivo in tumour cell lines and tumour xenografts in order to understand the therapeutic potential of the preparation.

The in vitro anti-proliferative activity of AMT was evaluated in panels of permanent human tumour cell lines and human tumour xenografts growing as colonies in soft agar. AMT showed concentration-dependent and selective inhibition of proliferation in several human tumour cell lines of cervical cancer, colon cancer, glioblastoma, ovarian cancer, leukaemia, and lymphoma. These findings provide evidence for the antineoplastic potency of AMT. Using a clonogenic assay, AMT was further characterized for its ability to inhibit anchorageindependent growth and in vitro colony formation of tumour cells in semi-solid medium. The test panel of 98 tumours, representing 19 different tumour types, aimed to reflect the heterogeneity of human tumours seen in clinical studies. The tumour cell preparations for the clonogenic assay were prepared directly from human tumour xenografts growing in nude mice. Based on the heterogeneity of growing solid tumour, these preparations comprised tumour stem cells to a certain extent which are discussed to be responsible for the metastatic and infiltrative potential of a tumour (16-20). Hence, the clonogenic assay reflects better the in vivo situation than in vitro assays using permanent tumour cell lines and has been found to be a predictive test for further in vivo evaluation of anti-cancer drugs $(9,21-24)$. AMT inhibited colony formation of tumour cells in semi-solid medium, and based on the distribution of $\mathrm{IC}_{50}$ values, tumour types such as cervical cancer, colon cancer, glioblastoma, leukaemia, melanoma, and pancreatic cancer were identified to be most sensitive towards AMT. Based on $\mathrm{IC}_{50}$ values, these sensitive tumour models were on average $\sim 4$-fold more sensitive than the mean $\mathrm{IC}_{50}$ of all models tested, indicating a tumour selective way of growth inhibition. Moreover, these sensitive tumour models were slightly more sensitive than haematopoietic stem cells as representative model system for non-malignant tissue. Thus, inhibition of colony formation of haematopoietic stem cells was in an acceptable range.

In order to allocate the anti-tumour activity of AMT to an active constituent, the single components of AMT were tested in comparison to the whole formulation in four different 
tumour models. There was clear anti-tumour activity of part, but not all of the components. Calcium Sandoz + Vitamin C, the aqueous camomile extract and phenol showed most inhibition of colony formation. However, the activity of AMT was strikingly higher than that of any single component. Thus, the anti-tumour activity of AMT benefits from the combination of all single components. Besides the aqueous camomile extract, calciumglubionate is present in the mixture at the highest concentration of all single compounds, and activity of Calcium Sandoz + Vitamin C could be demonstrated in the present study. Calcium as a ubiquitous second messenger regulates many cellular functions, including cell growth, differentiation and apoptosis (25-27). In addition, it was shown by several groups, that calcium can slow down cancer cell division, and administration of calcium offers an approach to the primary prevention of intestinal neoplasia and/or therapy of colorectal cancer metastases (28-30). In this manner, calcium probably contributes to the anti-tumour activity of AMT. But clearly, progress towards the clinical use of AMT will require detailed investigation into the precise role of each of its constituents.

In subsequent in vivo studies in tumour xenografts, established in immune-deficient nude mice, administrations of AMT at doses of 0.12 or $0.06 \mathrm{ml} / \mathrm{mouse} /$ day, respectively, were well tolerated. The dose level of $0.12 \mathrm{ml} / \mathrm{mouse} /$ day corresponds to $3.6 \mathrm{ml} / \mathrm{kg} / \mathrm{day}$, equal to $6.48 \mathrm{ml} / \mathrm{m}^{2}$ body surface (31). This dose is in agreement with the dose used in the clinical set-up with cancer patients who are treated with $5 \mathrm{ml}$ AMT twice daily, equal to $10 \mathrm{ml} /$ patient/day, or $5.56 \mathrm{ml} /$ $\mathrm{m}^{2}$ body surface. Slight anti-tumour activity was observed in a well differentiated, papillary breast adenocarcinoma, derived from a lung metastasis of a 51-year old female patient (MAXF 401), as well as in the murine melanoma B-16, and the murine colon adenocarcinoma colon 38. However, tumour growth inhibition was not significant, and not as pronounced as the respective positive control paclitaxel in case of MAXF 401. Significant inhibition of tumour growth was observed in a colon adenocarcinoma xenograft model, derived from an abdominal wall metastasis of a 61-year old male patient (CXF 1753), but tumour growth inhibition was not as pronounced as the positive control 5-fluorouracil in this model.

The immune stimulating potency of AMT was shown in experiments with isolated PBMCs, where AMT induced the secretion of IL- 6 and TNF- $\alpha$. IL- 6 , also known as interferon$\beta_{2}$ (IFN- $\beta_{2}$ ), T-cell replacing factor (TRF)-like factor, B cell differentiation factor (BCDF), B-cell stimulatory factor-2 (BSF-2), hybridoma-plasmacytoma growth factor (HPGF), hepatocyte stimulating factor (HSF), or monocytegranulocyte inducer type-2 (MGI-2), is a multifunctional cytokine which is produced by a variety of cells including $\mathrm{T}$ - and $\mathrm{B}$ cells and monocytes. IL- 6 regulates immune responses, acute phase reactions and haematopoiesis (32-35), and is involved in $\mathrm{T}$ cell activation, growth and differentiation $(35,36)$. It is known to induce serine esterase and perforin which are required for target cell lysis in the granules of cytotoxic T cells $(37,38)$ which are described to play an important role in the direct recognition and killing of immunogenic tumour cells. IL-6 has shown activity against cancer cells $(39,40)$, but was also found to be a growth factor for myeloma cells $(41,42)$. TNF- $\alpha$ is produced by immune cells including $\mathrm{T}$ cells, B cells, NK cells and monocytes. $\mathrm{TNF}-\alpha$ was originally characterized as an anti-tumour protein inducing necrosis of MethA sarcomas in vivo (43). TNF- $\alpha$ has been extensively studied and considered as an anti-tumour drug. It was applied intra-tumourally in cancer patients and some efficacy could be observed $(44,45)$. However, the use of TNF- $\alpha$ as a single systemic agent in high doses has shown toxic side effects $(46,47)$. Mechanisms of action, that have been suggested for the anti-tumour effect of TNF- $\alpha$, include direct cytotoxicity against tumour cells, activation of immune anti-tumour response and selective damage of tumour blood vessels (48). In acute phase reactions which occur e.g. during early phases of an infection IL- 6 and TNF- $\alpha$ have a wide spectrum of biological activities that help to coordinate the body's response. Some of the effects e.g. increased activation of B- and T lymphocytes and phagocytosis, are also important in anti-tumoural immune responses. The secretion of IL- 6 and TNF- $\alpha$ was induced during incubation of PBMCs with AMT. It has been described that aqueous extracts of the European mistletoe (Viscum album L.) also stimulate immunological relevant immune effector cells like macrophages, natural killer cells, as well as B- and T lymphocytes with subsequent release of cytokines, such as IL-1, IL-6, IL-10, TNF- $\alpha$ and granulocyte macrophage colony stimulating factor (49-53). These effects contributed to the established use of such extracts for stimulation of the immune system in patients suffering from malignant tumours (54).

At present, AMT is under the development as an anticancer agent. From compassionate use programs among end-stage cancer patients in the Middle East since 1989, preliminary data have provided evidence of benefits in terms of improved quality of life, sometimes together with body weight gain and reduction of pain. During clinical studies, it would now be of interest also to monitor cytokine levels in serum of patients before and after treatment. The immune stimulatory potential of AMT together with the slight antitumour efficacy observed in the present study indicate a role of AMT in tumour therapy.

\section{References}

1. Stein GM, Schietzel M and Bussing A: Mistletoe in immunology and the clinic. Anticancer Res 18: 3247-3249, 1998

2. Beuth J: Clinical relevance of immunoactive mistletoe lectin I. Anticancer Drugs 8 (Suppl 1): 53-55, 1997.

3. Grossarth-Maticek R, Keine H, Baumgartner SM and Ziegler R: Use of Iscador, an extract of European mistletoe (Viscum album), in cancer treatment: prospective nonrandomized and randomized matched-pair studies nested within a cohort study. Altern Health Med 7: 57-66, 68-72, 74-76, 2001.

4. Burger AM, Mengs U, Schüler JB and Fiebig HH: Antiproliferative activity of an aqueous mistletoe extract in human tumor cell lines and xenografts in vitro. Arzneim-Forsch/Drug Res 51: 748-757, 2001

5. Burger AM, Mengs U, Schüler JB and Fiebig HH: Anticancer activity of an aqueous mistletoe extract (AME) in syngenic murine tumor models. Anticancer Res 21: 1965-1968, 2001.

6. Dengler WA, Schulte J, Berger DP, Mertelsmann R and Fiebig HH: Development of a propidium iodide fluorescence assay for proliferation and cytotoxicity assays. Anticancer Drugs 6: 522-532, 1995

7. Fiebig HH, Dengler WA and Roth T: Human tumor xenografts: predictivity, characterization, and discovery of new anticancer agents. In: Relevance of Tumor Models for Anticancer Drug Development. Contrib. Oncol. Fiebig HH and Burger AM (eds). Karger, Basel, pp29-50, 1999. 
8. Fiebig HH, Berger DP, Dengler WA, Wallbrecher E and Winterhalter BR: Combined in vitro/in vivo test procedure with human tumor xenografts. In: Immunodeficient Mice in Oncology. Contrib. Oncol. Fiebig HH and Berger DP (eds). Karger, Basel, pp321-351, 1992

9. Fiebig HH, Maier A and Burger AM: Clonogenic assay with established human tumour xenografts: correlation of in vitro to in vivo activity as a basis for anticancer drug discovery. Eur J Cancer 40: 802-820, 2004

10. Nissen-Druey C, Tichelli A and Meyer-Monard S: Human hematopoietic colonies in health and disease. Acta Haematol 113: 5-96, 2005.

11. Fiebig HH and Schüler JB: In vivo antitumor activity of 5-methylindirubin. In: Indirubin, the Red Shade of Indigo. Meijer L, Guyard N, Skaltsounis L, Eisenbrand G (eds). Life in Progress Editions, Roscoff, Chapter 21, pp209-213, 2006

12. Laakmann G, Dienel A and Kieser M: Clinical significance of hyperforin for the efficacy of Hypericum extracts on depressive disorders of different severities. Phytomedicine 5: 435-442, 1998.

13. Szegedi A, Kohnen R, Dienel A and Kieser M: Acute treatment of moderate to severe depression with hypericum extract WS 5570 (St John's wort): randomised controlled double blind noninferiority trial versus paroxetine. BMJ 330: 503-507, 2005.

14. Kasper S, Anghelescu IG, Szegedi A, Dienel A and Kieser M Superior efficacy of St John's wort extract WS 5570 compared to placebo in patients with major depression: a randomized, double-blind, placebo-controlled, multi-center trial. BMC Med 4: 14-26, 2006.

15. Dimpfel W and Suter A: Sleep improving effects of a single dose administration of a valerian/hops fluid extract - a double blind, randomized, placebo-controlled sleep-EEG study in a parallel design using electrohypnograms. Eur J Med Res 13: 200-204, 2008.

16. Reya T, Morrison SJ, Clarke MF and Weissman IL: Stem cells, cancer and cancer stem cells. Nature 414: 105-111, 2001.

17. Tu SM, Lin SH and Logothetis CJ: Stem-cell origin of metastasis and heterogeneity in solid tumours. Lancet Oncol 3: 508-513, 2002.

18. Al-Haij M, Wicha MS, Benito-Hernandez A, Morrison SJ and Clarke MF: Prospective identification of tumorigenic breast cancer cells. Proc Natl Acad Sci USA 100: 3983-3988, 2003.

19. Pardal R, Clarke MF and Morrison SJ: Applying the principles of stem-cell biology to cancer. Nat Rev Cancer 3: 895-902, 2003.

20. Beachy PA, Karhadkar SS and Berman DM: Tissue repair and stem cell renewal in carcinogenesis. Nature 432: 324-331, 2004

21. Berger DP, Henss H, Winterhalter BR and Fiebig HH: The clonogenic assay with human tumor xenografts: evaluation, predictive value and application for drug screening. Ann Oncol 1: 333-341, 1990 .

22. Von Hoff DD: Human tumor cloning assays: application in clinical oncology and new antineoplastic agent development. Cancer Met Rev 7: 357-371, 1988.

23. Scholz CC, Berger DP, Winterhalter BR, Henss H and Fiebig HH Correlation of drug response in patients and in the clonogenic assay with solid human tumor xenografts. Eur J Cancer 26 901-905, 1990

24. Fiebig HH and Burger AM: Human tumor xenografts and explants. In: Tumor Models in Cancer Research. Teicher BA (ed) Humana Press, Totowa, pp113-137, 2001.

25. Dolmetsch RE, Lewis RS, Goodnow CC and Healy JI: Differential activation of transcription factors induced by $\mathrm{Ca}^{2+}$ response amplitude and duration. Nature 386: 855-858, 1997.

26. McConkey DJ and Orrenius S: The role of calcium in the regulation of apoptosis. Biochem Biophys Res Commun 239: 357-366, 1997.

27. Demaurex N and Distelhorst C: Apoptosis - the calcium connection. Science 300: 65-67, 2003.

28. Pitari GM, Zingman LV, Hodgson DM, Alekseev AE, Kazerounian S, Bienengraeber M, Hajnóczky G, Terzic A and Waldman SA: Bacterial enterotoxins are associated with resistance to colon cancer. Proc Natl Acad Sci USA 100: 2695 2699,2003

29. Penman ID, Liang QL, Bode J, Eastwood MA and Arends MJ Dietary calcium supplementation increases apoptosis in the dista murine colonic epithelium. J Clin Pathol 53: 302-307, 2000.

30. Buset M, Lipkin M, Winawer S, Swaroop S and Friedman E: Inhibition of human colonic epithelial cell proliferation in vivo and in vitro by calcium. Cancer Res 46: 5426-5430, 1986.
31. Freireich EJ, Gehan EA, Rall DP, Schmidt LH and Skipper HE: Quantitative comparison of toxicity of anticancer agents in mouse, rat, hamster, dog, monkey and man. Cancer Chemother Rep 50: 219-244, 1966.

32. Sehgal PB, Grienger G and Tosata G: Regulation of the acute phase and immune responses: interleukin-6. Ann NY Acad Sci 557: 1-583, 1989.

33. Heinrich PC, Castell JV and Andus T: Interleukin-6 and the acute phase response. Biochem J 265: 621-636, 1990.

34. Van Snick J: Interleukin-6: an overview. Annu Rev Immunol 8: 253-278, 1990.

35. Hirano T: The biology of interleukin-6. Chem Immunol 51: $153-180,1992$

36. Houssiau F and Van Snick J: IL6 and the T-cell response. Res Immunol 143: 740-743, 1992

37. Takai Y, Wong GG, Clark SC, et al: B cell stimulatory factor-2 is involved in the differentiation of cytotoxic T lymphocytes. J Immunol 140: 508-512, 1988

38. Liu CC, Joag SV, Kwon BS, et al: Induction of perforin and serine esterases in an murine cytotoxic $\mathrm{T}$ lymphocyte clone. J Immunol 144: 1196-1201, 1990 .

39. Shen WH, Zhou JH, Broussard SR, et al: Proinflammatory cytokines block growth of breast cancer cells by impairing signals from a growth factor receptor. Cancer Res 62: 4746-4756, 2002.

40. Danforth DN Jr and Sgagias MK: Interleukin-1 alpha and interleukin-6 act additively to inhibit growth of MCF-7 breast cancer cells in vitro. Cancer Res 53: 1538-1545, 1993.

41. Kawano MM, Ishikawa H, Tsuyama N, et al: Growth mechanism of human myeloma cells by interleukin-6. Int J Hematol 76 : 329-333, 2002.

42. Cheung WC and Van Ness B: Distinct IL-6 signal transduction leads to growth arrest and death in B cells or growth promotion and cell survival in myeloma cells. Leukemia 16: 1182-1188, 2002

43. Carswell EA, Old LJ, Kassel RL, et al: A endotoxin-induced serum factor that causes necrosis of tumors. Proc Natl Acad Sci USA 72: 3666-3670, 1975

44. Pfreundschuh MG, Steinmetz HT, Tuschen R, et al: Phase I study of intratumoral application of recombinant tumor necrosis factor. Eur J Cancer Clin Oncol 25: 379-388, 1989.

45. Lienhard D, Ewalenko P, Delmotte JJ, et al: High-dose recombinant tumor necrosis factor $\alpha$ in combination with interferon- $\gamma$ and melphalan in isolation perfusion of the limbs for melanoma and sarcoma. J Clin Oncol 10: 52-60, 1992.

46. Blick M, Sherwin SA, Rosenblum M, et al: Phase I study of recombinant tumor necrosis factor in cancer patients. Cancer Res 47: 2986-2989, 1987.

47. Spriggs DR, Sherman ML, Michie H, et al: Recombinant tumor necrosis factor administered as a 24-hour intravenous infusion. A phase I and pharmacologic study. J Natl Cancer Inst 80: 1039-1044, 1988.

48. North RJ and Havell EA: The antitumor function of tumor necrosis factor (TNF). II. Analysis of the role of endogenous TNF in endotoxin-induced hemorrhagic necrosis and regression of an established sarcoma. J Exp Med 167: 1086-1099, 1988.

49. Hajo $\mathrm{T}$ and Lanzrein C: Natural killer and antibody-dependent cell-mediated cytotoxicity activities and large granular lymphocyte frequencies in Viscum album-treated breast cancer patients. Oncology 43: 93-97, 1986.

50. Hajo T, Hostanska K and Gabius HJ: Modulatory potency of the $\beta$-galactoside-specific lectin from mistletoe extracts (Iscador) on the host defense system in vivo in rabbits and patients. Cancer Res 49: 4803-4808, 1989.

51. Hajo T, Hostanska K, Frei K, et al: Increased secretion of tumor necrosis factor- $\alpha$, interleukin- 1 , and interleukin- 6 by human mononuclear cells exposed to the $\beta$-galactoside-specific lectin from clinically applied mistletoe extract. Cancer Res 50 3322-3326, 1990

52. Hajo T, Hostanska K, Spagnoli GC, Fischer J, Lentzen H and Herrmann R: A plant lectin derived from Viscum album induces cytokine gene expression and protein production in cultures of human peripheral blood mononuclear cells. Nat Immun 14: 295-304, 1995

53. Schink M: Mistletoe therapy for human cancer: the role of natural killer cells. Anti-Cancer Drugs 8 (Suppl 1): 47-51, 1997.

54. Bocci V: Mistletoe (Viscum album) lectins as cytokine inducers and immunoadjuvant in tumor therapy. A review. J Biol Reg Homeos Agents 7: 1-6, 1993. 